\title{
SEMIOSES E METAMORFOSES
}

\author{
François RASTIER (D) \\ Centre National de la Recherche Scientifique (CNRS)
}

RESUMO

Independentemente das teorias gerativas e enunciativas, o estruturalismo dinâmico de tradição saussuriana permitiu formular o problema da semiose, compreendida como a individuação do signo, a partir de um germe estrutural. Num patamar superior de complexidade, os processos que presidem a esta individuação parecem também direcionar a composição dos textos. Exemplos literários e picturais permitem percebê-los; eles demonstram que a reflexão sobre as artes é uma área maior da semiótica geral e comparada.

ఠ

OPEN ACCESS

EDITORES

- Miguel Oliveira, Jr. (UFAL)

- René Almeida (UFS)

\section{AVALIADORES}

- José Saraiva (UFC)

- Carolina Lemos (UFC)

TRADUTORAS

- Rosalice Pinto (UNL)

- Isabel Muniz-Lima (UFC)

- Alena Ciulla (UFRGS)

- Mônica Cavalcante (UFC)

DATAS

- Recebido: 18/12/2020

- Aceito: 24/01/2021

- Publicado: 06/03/2021

COMO CITAR

RASTIER, François (2021). Semioses e

Metamorfoses. Cadernos de

Linguística, v. 2, n. 1, e344.

\section{ABSTRACT}

Independently of the generative and enunciative theories, the dynamic structuralism of the Saussurian tradition has made it possible to pose the problem of semiosis, understood as the individuation of the sign from a structural germ. At a higher level of complexity, the processes that preside over this individuation seem to also govern the composition of texts. Literary and pictorial examples make it possible to detect them; they confirm that reflection on the arts is a major area of general and comparative semiotics

\section{PALAVRAS-CHAVE}

Criação; Semiose; Individuação; Germe Estrutural; Composição.

\section{KEYWORDS}

Creation; Semiosis; Individuation; Structural Germ; Composition. 


\section{INTRODUÇÃO'}

As perguntas recorrentes a respeito do lugar da semiótica não têm resposta unificada, porque, pelo fato de não haver regência, o projeto intelectual das ciências da cultura, a semiótica hesita em determinar seu objeto, seu campo específico (o "Sentido " será um deles?), e se apresenta, há meio século, como um "projeto" necessariamente impreciso, na esperança de que esteja mais de acordo com os acontecimentos atuais, não sem multiplicar, contudo, os gestos fundadores.

Como, então, ver o que não se viu? Não basta amainar os confrontos com outras teorias, com outras correntes problemáticas (Saussure, Cassirer, Panofsky). É necessário ultrapassar a especulação dedutiva, ao desenvolver o procedimento crítico que se opõe a ele: tal aprofundamento epistemológico é o único que pode abrir uma capacidade descritiva.

\section{A SEMIÓTICA COMO TEORIA DA CRIAÇÃO E DA TRANSFORMAÇÃO DOS SIGNOS}

Adrien Naville diz, quanto à semiologia de Saussure, que seu "objeto seriam as leis da criação e da transformação dos signos e de seu sentido". Sem terem de ser "essencializadas", as estruturas não são simplesmente momentos de estabilidade, mas invariantes que caracterizam formas recorrentes. A identificação dessas formas não esgota a descrição: é só o começo, uma vez que elas só são inteligíveis numa série de transformações, para as quais elas são momentos singulares. A rede de suas relações considera, além do mais, normas de organização: por exemplo, o quiasma, tanto semântico quanto expressivo, parece uma norma de organização onipresente, que encontramos também na literatura, e na música ou na pintura ${ }^{3}$.

A questão das transformações está no centro da teoria estruturalista, sobretudo a partir dos trabalhos de Cassirer, inspirados na teoria dos grupos formulada por Felix Klein, como "O conceito de grupo e a teoria da percepção4». Eles lançam luz sobre um estruturalismo

1 Texto original: Revista Semiótica, 2020, n. 234, p. 145-162. Disponível em: https://doi.org/10.1515/sem-2018-0129.

2 Nouvelle classification des sciences. Étude philosophique, Paris, Alcan, 1901, p. 104. o "quadrado semiótico " apresentado por Greimas et Rastier era, primeiramente, concebido como uma estrutura de transformações de conteúdos lexicais desdobrados em percurso, depois, em transformações narrativas.

3 Como as marcas luminescentes que emolduram a Véronique du Pontormo, no claustro de Santa Maria Novella. (Verônica é a mulher que enxuga o rosto de Jesus Cristo, e Pontormo, o pintor).

4 Traduzido em francês por Paul Guillaume e publicado em 1938 no n 35 do Journal de psychologie normale et pathologique (pp. 368-414). 
dinâmico, que, tendo como foco o conceito de grupo de transformações, enraíza-se na matemática do Programa de Erlangen. Por sua vez, o "quadrado semiótico" foi vinculado a um grupo de Klein por vários autores, sobretudo, Frédéric Nef; ele recebeu, ele recebeu, em seguida, de Jean Petitor, uma interpretação topológica em Morphogenèse du Sens (1985) 5 .

Deve-se recusar a imagem consensual de um estruturalismo logicista e simplificador. No início dos anos 1940, Cassirer, Jakobson e Lévi-Strauss estavam muito próximos e participaram, os três, do primeiro número de Word, publicado em 1945. Foi uma espécie de manifesto de um estruturalismo estendido ao conjunto das ciências da cultura.

Este estruturalismo tem como objetivo definir o modo de objetividade específico dos objetos culturais. A busca de invariantes se torna, então, decisiva, segundo Cassirer: "Dada uma multiplicidade (Mannigfaltigkeit) e um conjunto de transformações ligadas a ela, o problema consiste em estudar os elementos desta multiplicidade de pontos de vista de propriedades que não são operadas pelo grupo". ${ }^{6}$

A noção de grupo de transformações sustenta, então, uma nova concepção da objetividade: um objeto é constituído por um conjunto de invariantes e de variantes em uma série de transformações. Isso resolve o antigo problema da relação entre a substância e os acidentes, relativiza a relação entre necessidade e contingência, e afasta as aporias do dualismo: por exemplo, a ideia de triângulo é a soma das invariantes dos triângulos empíricos, mas ela lhes é imanente e não transcendente. A série das transformações é um corpus interno, que constitui uma identidade sempre em mudança em relação a si mesma. As categorias transcendentais ou cognitivas não são nem necessárias nem pertinentes, porque somente os contextos são constitutivos. Qualquer morfologia é incorporada, sendo, assim, semiótica; ou, mais precisamente, qualquer signo se origina do regime geral das morfologias.

A teoria do conhecimento por abstração e presunção torna-se, então, inadequada: "O trabalho do espírito não consiste em colocar o conteúdo sob um outro conteúdo: consiste em especificá-lo como um conjunto de transformações concretas, mas indiferenciadas, operadas pelo grupo». A noção de grupo de transformações suporta, então, uma nova concepção, destacando um momento característico e focando o ponto para o qual a "atenção é direcionada"? Isso resulta numa ruptura com a tradição ontológica, uma vez que os "modos de ser" característicos das diversas instituições simbólicas podem ser, então, diferenciados. ${ }^{8}$

5 Ver, agora, David Piotrowski, Morphogenesis of the Sign, New York: Springer, 2017.

6 Manuscrito MS \#214, Nachgelassene Manuskripte und Texte, vol. 8, Hambourg, Meiner, 2008: 187-188.

7 Ernst Cassirer (1972a), p. 252 (ECW 11: 254-255).

8 É o sentido do debate de Davos com Heidegger, quando Cassirer declara: « O que há de novo nessa reviravolta, parece-me resistir ao fato de que tal estrutura ontológica não é, doravante, única, mas que temos à nossa disposição estruturas ontológicas muito diversificadas. Qualquer estrutura ontológica nova supõe novas 
Realmente, não temos mais em foco objetos, mas objetivações, como havíamos observado em relação à semiose para Saussure, quando ele se afasta decisivamente da concepção comum que reduz a língua a palavras e regras. Cassirer escreve assim: "O ‘dado' do objeto se transforma, então, em "tarefa” da objetividade. Tarefa da qual, como podemos demostrar, o conhecimento teórico não é o único a participar, já que qualquer energia do espírito toma parte disso à sua maneira. Doravante, a linguagem e a arte, também elas, se atribuem sua significação "objetiva" original, não porque elas reproduzem uma realidade existente, mas porque elas a prefiguram e são modos e direções da objetivação?.

Assim, a teoria da arte torna-se diretriz e se reveste de um alcance epistemológico geral que faz dela uma espécie de filosofia primeira ou pelo menos uma área exemplar, dentro da filosofia das instituições simbólicas. Pode-se compreender nesse sentido a proposta de Cassirer sobre « o coração da linguagem em si, que se deve procurar muito mais na estilística do que na gramática $"{ }^{10}$ Se a linguagem e a arte se tornam "formas simbólicas» maiores, é porque a transportabilidade das estruturas adquire uma importância maior. Enquanto arte da linguagem, a literatura torna-se um lugar exemplar de investigação, a tal ponto que a iconologia de Panofsky leva em conta, de forma acentuada, as fontes literárias que podem esclarecer as dificuldades interpretativas encontradas pela reflexão iconográfica.

Além do mais, nem sempre se tem medido o alcance teórico das metáforas musicológicas no grande ciclo de Lévi-Strauss sobre os mitos ameríndios. Se testemunham um humor cultivado, elas propõem um repertório de transformações, como o canhão, a fuga etc..., e de modos de composição, como o contraponto. As artes "abstratas", como a música, têm sistematicamente refletido a respeito do método das transposições, com as variações, diminuições etc. Tais instrumentos metodológicos tomam retrospectivamente um alcance epistemológico geral para as ciências das instituições simbólicas. Cada uma dessas instituições, direito, arte, técnica, linguagem, religião, economia etc., têm, é claro, suas especificidades, mas a reflexão comparativa sobre os modos de individuação"1 dos diversos objetos culturais só está começando. Contudo, pela dimensão crítica de sua criação, as obras de arte parecem poder se tornar um paradigma do objeto cultural e continuar a sê-lo pela sua indeterminação, ou melhor, sua "metaestabilidade" (metastabilitê)

condições a priori. [...]. Aí se introduz uma diversidade realmente nova para o problema do objeto em geral. [...] O ser da antiga metafísica não é mais, para falar minha linguagem, o ser de uma substância, mas o ser que procede de uma pluralidade de determinações e significados funcionais. É aqui que me parece residir o ponto essencial em que minha posição difere da de Heidegger (Cassirer 1972b, pp. 48-49. Passamos assim de geometrias nãoeuclidianas para ontologias não-parmenidianas).

9 "L'objet de la science de la culture", in Logique des sciences de la culture, Paris, Cerf, 1991, p. 108.

101972 a, p. 72

11 A “individuação" (individuation) corresponde à formação dos objetos pela teoria de Georges Simondon. 
que faz de sua abertura a manifestação de uma liberdade exemplar ou, até mesmo, paradoxalmente sem limites previsíveis.

\section{ESTRUTURA E FORMAS}

Por precaução epistemológica, estimamos que a invariante não seja dada (não há estrutura profunda a priorl), salvo se admita, por exemplo, a hipótese, muito forte, reivindicada por René Thom e Bernard Pottier, de um paralelismo entre os processos físicos elementares e as regras linguísticas da predicação. À estrutura como tipo a priori, ou meio esquemático de negociar conceitos universais, oporemos uma outra concepção da estrutura, como hipótese reguladora. Para nosso uso, nós a recusaremos como a invariante de uma série de transformações, que interessam a um grupo de formas semióticas. Esta série pode ser fechada (num texto), mas pode se abrir caso se estenda o corpus a outros textos. Perguntas se colocam [se impõem?]: a estrutura é um tipo? Entre suas ocorrências, deve-se privilegiar as recorrências ou as diferenças?

\section{O tipo e a linhagem}

Frequentemente, definiu-se a estrutura como abstração de uma série de ocorrências: por exemplo, em lexicografia, o lema ("lemme", em francês) resume uma série de ocorrências léxicas, sem que se dê importância às suas localizações e à sequencialidade do texto.

A questão da subsunção pode, então, se colocar: todas as ocorrências são conhecidas por instanciar o tipo, numa lógica das classes e em representação dos conhecimentos, tal como se dá nas eternas questões sobre os pássaros que não voam e os tigres de três patas. Tal modelo clássico teve a concorrência das teorias do pertencimento ou do "ar de família": uma série de formas poderiam não compartilhar de forma unânime um só ponto em comum, enquanto que cada uma compartilha com algumas outras pontos em comum, bastante caracterizados, para serem percebidas como membros da família. A família, ou pelo menos seu "ar" de família, não é, contudo, uma estrutura, mas uma nuvem de pontos fortemente associados, ou mesmo conectados: pode-se, assim, caracterizar a molécula "sêmica", que se abriu, para pesquisas posteriores, sobre a temática e o reconhecimento de forma semânticas "ruidísticas" (o autor, 1987, cap., 7). Todavia, por uma concepção morfológica da ontologia, a relação entre tipo e ocorrência torna-se uma relação entre pré-individual e o individualizado. A estrutura tem como origem, então, momentos pré-individuais. Esta hipótese permite caracterizar o estruturalismo morfológico, que difere da imagem preconcebida de um estruturalismo lógico, inspirado no binarismo jakobsoniano. 


\section{Privilegiar a identidade ou a diferença?}

As formas semióticas são complexas e, como tal, jamais idênticas a elas mesmas (cada ocorrência é um hápax), nem completamente diferentes (assim, até a conversão de Dom Juan de Molière à hipocrisia não o faz mudar de nome $)^{12}$. Também vemos que somente a metodologia comparativa permite agrupamentos baseados, ainda que evolutivos, porque, longe de dar ruídos ao sentido, ela consegue defini-la por um feixe de diferenças pertinentes.

Duas concepções se enfrentam tradicionalmente: a ontologia parmenidiana (depois, newtoniana-hamiltoniana) privilegia a invariabilidade, determinada pela tradição lógicogramatical; a ontologia de tradição heraclitiana privilegiava a variação e se apoiou na problemática retórico-hermenêutica que preside à semântica dos textos e à linguística de corpus. Diferentemente das estruturas lógicas, as estruturas dos objetos culturais conhecem evoluções constantes, assim como as instituições simbólicas que as elaboram. Também as ciências da cultura não postulam leis, procuram, entretanto, identificar condições e, nos casos favoráveis, hierarquizá-las.

Segundo as culturas, os discursos e os gêneros, pode-se escolher privilegiar as permanências ou as transformações - até corresponder à, em Wölfflin, oposição entre clássico e barroco. Trata-se, aí, de uma dualidade que interessa a toda a descrição semiótica. Uma análise que privilegia as identidades corre o risco de projetar as mesmas estruturas em tudo, negligenciando as diferenças entre as ocorrências, diferenças que justamente fazem sentido. Por outro lado, um levantamento de diferenças torna-se, logo, artificial, como testemunha o relativismo inicial da hermenêutica desconstrucionista, explicitamente edificada desde os anos 1960 para pôr fim ao estruturalismo.

\section{FUNDOS E FORMAS}

Ultrapassando a dualidade hilemórfica forma/substância, a dualidade forma/fundo evoca, obviamente, um modelo gestaltista. Todavia, não nos referimos, aqui, à fenomenologia do campo perceptivo, mas à própria percepção do campo semiótico, tal como esta impõe sua organização à consciência. A fenomenologia, certamente, subjetivou a semiótica, enquanto nós tentamos objetivá-la. A redução fenomenológica proibiu, sobretudo, conceber o acoplamento semiótico da pessoa com seu meio semiótico, que, por sua própria legalidade, se impõe aos conteúdos da consciência: enfim, o semiótico não é constituído por conteúdos

\footnotetext{
12 A semiótica nada tem a ver nem com o sinal puro nem com o ruído puro, e ela deve, então, hierarquizar os graus de pertinência. Privada de sua complexidade, aparentemente supérflua, uma grandeza semiótica se torna estranha, sem interpretação. Como diz de forma enfática Thom: «Tudo que é rigoroso é insignificante» (1980, p. 292).
} 
de consciência, mas condiciona a formação desses conteúdos, correlatos eidéticos que não saberiam ser dotados de uma prioridade causal.

Se a Semântica interpretativa privilegiasse as isotopias, a organização dos conteúdos semânticos, Sens et textualité (Sentido e textualidade) definiria a interpretação como um percurso de formas semânticas ${ }^{13}$. Não é cedo demais para tornar precisa a complementaridade entre fundos e formas. A relação entre fundos e formas é intermediada por um campo que os inclui e cujos princípios de organização determinam o caráter semiótico da percepção do meio semiótico. O campo, assim estabelecido, não é uma «cena» que seria a involução de um espaço de conjunturas particulares, coisas já vistas, aliás, como em Scenes and Frames Semantics, de Fillmore, ou sua transposição na teoria das cenas de Victorri, retomada, atualmente, por Maingueneau.

Um "fundo" é um substrato contínuo que condiciona qualquer "discretização", na medida em que é percorrido por desigualdades, por conflitos de baixa intensidade que permitem percebê-lo. Passadas certas barreiras, em condições genéticas favoráveis, formas emergem do fundo. Acusando suas descontinuidades, tais formas se delimitam reciprocamente e evolvem sem cessar. A relação entre a totalidade do campo e as formas que aí se projetam se apresenta assim: o campo caracteriza a família das formas que dela saíram, emergindo, discretamente, umas das outras.

O tempo de constituição interna às formas é muito marcado pelas fases de sua individuação, e o que chamamos de traços básicos fenomenológicos são correlatos dos germes estruturais, dos quais elas saíram. Esse tempo, que se descreve como um «presente espesso ${ }^{14}$ », não se resume ao fluxo de consciência, é organizado pelo recorte das formas; aliás, de Santo Agostinho a Husserl, é a música, organização semiótica objetivada, que serve de termo de comparação para o tempo vivido.

\section{ENFORMAÇÕES ${ }^{15}$ E INDIVIDUAÇÃO DOS SIGNOS}

As normas e as formas que os concretizam ficam no pré-consciente dos locutores, em um segundo plano esquemático que leva em conta as formalizações sucessivas, durante a composição da sequência (sintagma, período ou texto). O percurso da ação produz um grupo semiótico, um após o outro, sem determinismo previsível, o que faz da produção uma criação, a cada vez singular, e não a aplicação de um projeto predeterminado por regras.

13 O autor, Sens et Textualité, Paris, Hachette (1989), p. 25.

14 Cadiot e Visetti (2001), p. 53.

15 (N. de T.) No original "prises de forme", conforme artigo já publicado por Lopes (2020), disponível em http://www.revistas.usp.br/esse/article/view/174819/163408. Corresponde à passagem de algo amorfo a algo estruturado, "en-formado". 
O nível esquemático subjacente é o das estruturas; ele autoriza, com relação às formas efetivas, duas hipóteses reguladoras complementares que interessam: os germes estruturais e a composição dos textos.

\section{1. OS GERMES ESTRUTURAIS}

Um campo semiótico saturado de diferenciações expressivas e semânticas pode se organizar em contato com um germe estrutural, uma molécula "sêmica" e/ou um grupo de traços fonológicos, que atrairá, em torno de si, elementos de forma, como contornos ou pontos singulares. O germe estrutural poderá, em seguida, favorecer várias individuações semióticas, cada uma diferindo, segundo a função de seu contexto de enformação. Estudemos, pois, os fenômenos de individuação, do nível do morfema até o do texto.

Frequentemente concebido como palavra escrita, e após a noção dicionarizada da língua como nomenclatura, o "signo" linguístico indiferenciado teria que ceder o seu lugar, desde sua formação da linguística, ao conceito de morfema.

Os morfemas são classicamente definidos pela prova da comutação, mas as hipóteses, frequentemente especulativas, sobre o nível inframorfêmico poderiam receber um novo foco a partir da teoria da individuação. Passemos às especulações de todos os esoterismos a respeito da significação das letras, sobre as reflexões, meio esotéricas, de autores como - Coronel Pictet ou Stéphane Mallarmé (em As palavras inglesas), ou mesmo sobre a hipótese de infrassignos fundamentais, que seriam "cognemas"na linguística cognitiva et "enativa" de Bottineau. Passemos também às especulações etimológicas, justamente recusadas por Saussure, que fariam de longínquas raízes fontes de significações presentes.

O problema de uma «protossemiose» foi colocado em 1967 numa obra maior de $\mathrm{Pi}$ erre Guiraud, que trata de protomorfismos et protossemantismos ${ }^{16}$ : por exemplo, a «raiz consonântica» $t$ k evocaria, em francês, um 'coup' (= golpe) e se encontra em diferentes lexemas não diretamente aparentados, como "toc" ou "taquet" (ver a expressão "mettre un taquet" para "frapper" (bater).

Os germes semióticos são uma espécie particular de germes estruturais: diferem dos germes orgânicos ou inorgânicos por uma complexidade própria e uma forte imprevisibilidade das produções, de onde saíram. Definem esboços de percursos genéticos e/ou interpretativos.

Composto de um sema e de um fema, semiotização elementar, o germe mínimo binário é um ponto singular instável, esperando um complemento. No patamar de complexidade imediatamente superior, o germe quaternário é um elemento de forma dual: sua parte 
semântica é uma molécula sêmica, e sua parte expressiva é constituída por uma molécula "fêmica" (agrupamento de traços fonológicos que pertence a um ou vários sememas).

Um germe semiótico reúne, assim, uma molécula sêmica e uma molécula fêmica. Em virtude da lei gestaltista de boa continuação, todas as duas são matrizes de isotopia ou de isofonia. ${ }^{17}$ Elas se traduzem por fenômenos formulares, onde a repetição de semas e de fonemas assegura a pregnância da forma e permite sua memorização. Por exemplo, nos feitiços, o nome do mal é emparelhado por paronímia àquele do santo que se imagina curar ou proteger. ${ }^{18}$ Esses processos são muito comuns em literatura, uma vez que a arte da linguagem explora, é claro, os princípios da semiose. Aqui estão dois exemplos.

No mesmo verso de um ghazal de Rûmi (XVI, v. 17) repete-se três vezes o mesmo grupo de três consoantes, ملك , que, variando suas vogais, significa respectivamente malek (rei), molk (território, país, reino), malak (anjo), essas três significações compreendendo o sema /domínio/.19 Essas três palavras são decalques do árabe no persa; ora, é sabido que nas línguas semíticas como o hebreu e o árabe, e pelo fato de que a escrita não considera as vogais, as raízes bilíteras ou trilíteras são consideradas como germes semióticos, suscetíveis de engendrar, de acordo com os contextos, grupos estendidos de lexemas semântica e expressivamente aparentados.

Num Oriente ainda mais místico que o de Rûmi, o dos rascunhos de Heródias, Flaubert multiplica as substituições: no décimo primeiro rascunho, ele transforma a coroa de pedra (folio 539 verso riscado) por carena de pedra ( $f^{\circ} 538 v^{\circ}$ riscado). A palavra carena provém da descrição da paisagem que circunda a fortaleza, onde as montanhas são comparadas, numa frase riscada, a "carenagens de navio" (sic; fo539 v riscado). O que unifica, então, carena e coroa, pois, são, justamente, os processos de secagem simbólica, numa novela dominada pela exposição à morte, sob a ordem do rei Antipas, de São João Batista, evidentemente associado à água. O mesmo tipo de paranomásia se repetia, à altura do décimo rascunho, no quase estranho que prepara a descrição do deserto da Judeia: " as grandes montanhas [...] [os cimos agudos <vagos> das montanhas [...] faziam aparecer suas arestas, parecidas com restos de cascos de embarcações emergindo de um oceano petrificado". Arestas reúnem o ressecamento e a mineralização, e evoca morte. Numa moldura, o folio 744 nos mostra que os soldados que o rei Antipas temia perceber na primeira descrição da paisagem eram "as tropas do rei [Arrêtas]"20. Assim às paranomásias carena/coroa e arestas/Arrêtas vêm juntar-se, no plano semântico, os dois traços /marítimo/ (/ressecado/, no contexto) e /real/ (/ameaçador/, no contexto).

\footnotetext{
17 Ver Paul Valéry : "a aglutinação da variável fonética e da variável semântica causa problemas de prolongamento e de convergência " (OEuvres, I, p. 1356).

18 Cf. Pierre Guiraud (1967), p. 106-107.

19 Amir Sedaghat (2015), p. 199, n. 300.

20 O autor (2018c), p. 194
} 
Ora a primeira frase acaba nas palavras Mar Morto. Segundo a teoria antiga da inicial significativa ${ }^{21}$, sempre presente nas bulas papais, cujas primeiras palavras indicam, ao mesmo templo o título e a orientação geral, as séries carena/coroa e arestas/Arrêtas são, provavelmente engendradas a partir da dualidade /marítimo/ (ressecado) e /fúnebre/ (ameaçador), já formuladas em Mar Morto.

Em lugares diferentes do mesmo campo, o mesmo germe semiótico poderá suscitar formas aparentadas. A classe das semelhanças metonímicas são testemunhas. Além do mais, as formas se transpõem por mudança de conteúdo e saem, então, do campo. Quando elas passam de um campo a um outro, resultam aparentadas, o que testemunham tropos como a comparação ou a metáfora.

A enformação é, ao mesmo tempo, guiada e exigida. Normas regem a enformação expressiva: por exemplo, fórmulas anagramáticas, paranomásias, esquemas métricos e quantitativos definem as boas formas expressivas. Outras normas regem a enformação semântica, pelas preferências de boa continuação isotópica, as isossemias, ecos analógicos, os quiasmas e outros ritmos semânticos etc. Tais normas estão para a obra, num processo de semiose que faz da constituição do signo o resultado de uma otimização local, como a palavra "justa" ou "bem posta”. Os gêneros com forma fixa/invariável exibem essas normas e colocam o leitor no curso de ação semiótica, ao mesmo tempo genérico e interpretativo: assim, a rima instala uma expectativa, e essa antecipação participa de uma emulação ou substituição imaginativa.

\section{2. GERME ESTRUTURAL E COMPOSIÇÃO DO TEXTO}

A composição obedece a uma dinâmica que regula tanto a individuação da obra quanto a de suas razões constitutivas.

\section{A hipótese da palavra-tema}

Uma primeira hipótese pode ser autorizada a partir de Saussure: "quem compunha um carme [...] devia se preocupar, assim, de uma maneira cuidadosa, com as sílabas que entravam nesse carme e com as rimas que elas formavam entre elas, ou com um determinado nome. Todo poeta era acima de tudo um especialista em fonemas. ${ }^{22}$ Saussure detecta, assim, nos poetas antigos, um conhecimento linguístico profundo: "Afirmo de fato (como sendo minha tese a partir daqui) que o poeta se dedicava, e tinha como profissão comum se dedicar à análise fonética das palavras: porque era essa ciência da forma vocal das

\footnotetext{
21 (N.T) No original, "initiale prégnante". A teoria patrística da inicial significativa supõe que as primeiras palavras de um texto determinam a sua leitura. É por isso que as bulas papais apresentam um início que também serve de título.

22 Saussure, in Benveniste (1964), p. 114.
} 
palavras que provavelmente dava superioridade, desde os mais antigos tempos indo-europeus, ou a qualidade particular, dos Kavis dos hindus, dos vātēs dos latinos etc". ${ }^{23}$

Para os antigos poetas indo-europeus, o germe estrutural poderia ser elaborado a partir do nome de um deus ou de um mortal e tornar-se o suporte de um desenvolvimento encomiástico. O nome não se expandia apenas em fonemas repetidos por aliterações e assonâncias: já era um signo, portanto dotado de um significado, e resultava assim de uma semiose exemplar, que poderia servir de germe estrutural na composição do texto.

No início dos anos 1970, um debate sobre a criação literária tomou o texto como a expansão de uma palavra, uma tese enigmática que se baseava no primeiro comentário de Starobinski sobre as pesquisas de anagramas de Saussure; daí, por exemplo, o livro de Derrida, La Dissémination. Este tema prolongava as especulações simbolistas, mas também ecoava o tema cabalístico que fazia do Torá a expansão do nome impronunciável do Senhor.

Porém, na prática literária, a palavra da qual extraímos o germe estrutural é escoIhida ou criada em função de um projeto. É o que explica Edgar Poe, num texto que teve grande influência na poesia simbolista, principalmente em razão de sua tradução por Baudelaire. Detalhando a gênese de The Raven, Poe escolhe "a impressão" ou "o efeito a ser produzido", depois o "meio para esse efeito", ou seja, uma palavra que servirá de refrão ao encerrar cada estrofe: "Que esta conclusão, esta queda, para ter força, tinha necessariamente que ser sonora e passível de uma ênfase prolongada, disso não se tinha dúvida, e essas considerações me levaram inevitavelmente ao o longo, por ser a vogal mais alta, associada ao $r$, que era a consoante mais vigorosa. ${ }^{24}$ Da próxima palavra escolhida, nevermore, deriva por paronomásia o nome da amada, Leonore, e por inversão raven; dessas três palavras, fluirá o poema.

Mallarmé adaptará, em seu nome, essa narrativa naturalmente questionável e que, por si só, faz parte do mito simbolista: "A mais bela página da minha obra será aquela que conterá apenas este nome divino: Herodias. A pouca inspiração que tive, devo a este nome, e acredito que, se a minha heroína se chamasse Salomé, eu teria inventado esta palavra sombria, e vermelha como uma romã aberta, Herodias ${ }^{25}$. Mais uma vez, tanto em Poe quanto em Mallarmé, o princípio de composição pode ser deduzido da natureza do germe estrutural.

23 Saussure (2013), p. 390. Saussure especifica, com hesitações reveladoras e marcadas por rasuras, como o tema que em nossa opinião assume a função de germe estrutural pode reger a elaboração do texto: "Acima de tudo, penetrar nas sílabas e combinações fônicas de toda espécie, que por acaso constituíram seu TEMA. Este tema escolhido por ele mesmo ou fornecido por quem paga a inscrição - é composto por apenas algumas palavras, seja somente por nomes próprios, ou por uma ou duas palavras juntas à parte inevitável dos nomes próprios. (Saussure in Testenoire 2013, p. 69). Eu me apoio bastante nesta seção no estudo de Testenoire "Saussure/Mallarmé": autópsia do acoplamento", a sair.

24 Poe (1982), p. 170

25 Mallarmé (1998), p. 669 
Certas formas organizadoras se prestam à extração de germes estruturais. Não se trata, necessariamente, de uma palavra inicial. Numa leitura linear, pode-se pensar em post hoc ergo propter hoc, mas ao examinar os rascunhos pensamos de modo diferente: um esboço comum pode dar origem a várias formas aparentadas, mas podem ser apagadas em seguida. Seus descendentes e ascendentes se desdobram na linearidade ideal da leitura, mas também na sucessão temporal dos textos do corpus.

Para distinguir mais claramente o germe estrutural da "palavra-tema", precisemos seu estatuto. Em qualquer classe lexical, pelo menos um termo é intenso (ou marcado), enquanto os outros são "extensos" (ou não marcados)": "A intensidade corresponde a uma valorização particular e dá ao termo uma energia limpa. Por exemplo, em latim, pecunia (cabeça de gado, riqueza por excelência), passa a designar o conjunto das riquezas; em francês antigo, "carne", um alimento valorizado, passou a significar todo o conjunto de refeições (como bife agora em ganhar seu bife) etc. ${ }^{26}$

Por sua valorização, as palavras-tema têm sem dúvida o estatuto de paradigmas dos quais se extraem, por exemplo, "mannequins" (termo que Saussure usa em suas pesquisas sobre anagramas), grupos de fonemas que assumem a função de germes estruturais a partir dos quais se buscam realizações variáveis.

Um germe estrutural permite uma estilização da forma que ele induz, por simplificação de contornos e por acentuação de pontos singulares, ou, nos termos da teoria dos sistemas dinâmicos, por levantamento dos colos, aprofundamento e alargamento de poços de potencial ou de bacias de atração. A forma estilizada atua como o que é chamado na etologia animal de "gatilhos supranormais" (supranormal releasers). ${ }^{27}$ São desvios fascinantes que exageram certos traços: quando a um pintinho é apresentada uma pirâmide vermelha briIhante, ele abre seu bico ainda mais vividamente do que diante de um bico parental. Sabese, pelo estudo do fetichismo, que para o homem o tamanho e a estilização dos estímulos também são desencadeadores.

\section{As formas predominantes de organização elementar}

Valéry tinha interiorizado este modo de composição: "Gostaria de começar com uma palavra isolada, substantiva ou qualificativa, como que para dar a ouvir um som cujas ressonância e harmonia se permite florescer. Depois, para retomá-la, e como que para procurar uma direção nesta atmosfera, e para particularizar pouco a pouco até... como que para encontrar o caminho para as combinações completas que constituirão a obra." (Cahiers, XXIII, p. 67). O morfema ou a palavra tomada como um germe estrutural é uma semiose realizada, valorizada, mas descontextualizada, e que, assim, nos permite organizar outras. 
Entretanto, podem ser sinais compostos, ou mesmo passagens. Em outras semióticas, os modelos poderiam ser formas visuais, musicais etc.

A caracterização do germe estrutural responde parcialmente à questão dos princípios organizacionais recorrentes que podem caracterizar um trabalho e tendem a presidir sua gênese. Leo Spitzer foi muitas vezes criticado por criar, como o princípio de leitura,uma figura, seja ela um tropo ou não, mas nada permite evitar que uma figura possa assumir os poderes de um germe estrutural. Formulamos assim esta hipótese sobre a hipálage em Borges, que preside inversões em todos os níveis de análise, e tanto no plano do conteúdo quanto no plano da expressão. ${ }^{28}$

Esse problema parece geral e ultrapassa, naturalmente, a literatura. Por exemplo, a figura do diedro é, sem dúvida, um dos grandes princípios composicionais da famosa deposição de Rosso em Volterra: encontramos, sob os pés de Cristo, o supedâneo colocado no cruzamento central das diagonais da composição patêmica, na manga e no quadril de Madalena etc. Ela também justifica o adjetivo cubista com que alguns críticos equiparam esta pintura. Permite não só uma esfoliação particular do espaço em vários planos exploratórios, mas também efeitos de cor e luz, e a multiplicação dos membros dobrados, nas atitudes da maioria dos personagens, retoma esses ângulos em outras escalas: este é o caso não só da barba de José de Arimateia, dos membros do próprio Cristo, mas também dos braços e pernas dos quatro homens que desprenderam o corpo, com a significativa exceção do braço estendido, que designa a ferida aberta pela lança. Este princípio composicional pertence ao estilo da obra, mesmo que tais diédricos às vezes se encontrem dentro de dobras características do estilo do autor, como no Casamento da Virgem em Florença.

Orientações. - Não vamos evitar uma objeção: as palavras-tema poderiam muito bem advir da estética do simbolismo fim-de-século. No entanto, em um estudo fonoestilístico em um corpus digitalizado, Valérie Beaudouin (2002) mostrou que, nas tragédias de Racine, o nome do personagem epônimo via seus fonemas significativamente difundidos. A pesquisa saussuriana sobre os anagramas ainda precisa ser testada dessa forma. Em outras tradições poéticas, especialmente germânica e celta, a aliteração é estabelecida como um princípio composicional. O mesmo se aplica à poesia árabe e persa.

Damos prioridade aqui à isofonia e à isossemia, mas as experiências associacionistas há muito mostraram que o antônimo era sistematicamente reconhecido e produzido em um tempo muito menor do que em todos os elementos relacionados. Este estudo deve, portanto, ser continuado considerando fonemas e semas opostos, que definem uma segunda fase complementar da individuação semiótica, a das diferenças qualificadas como oposições. Elas integram o signo em seu contexto e the conferem negatividade, que completa a atualização das virtualidades promovidas pela energética do germe estrutural. 
Este estudo comportava inicialmente uma seção sobre as relações de transformações entre textos de um mesmo autor e entre textos de diferentes autores, em várias línguas. Por falta de espaço, tomaremos a liberdade de remeter o leitor a publicações anteriores (2006, 2007, 2018a, 2018b, 2018c).

\section{ORIENTAÇÕES DE PESQUISA}

Surge, assim, um regime triplo da semiose.

- Uma forma é caracterizada pela distribuição e relativo relevo de seus pontos singulares: estas diferenças internas constituem sua significação.

- No âmbito do mesmo desempenho semiótico, uma forma adquire significado em relação a outras formas comparáveis; por exemplo, os amantes de Emma Bovary, o cavaIheiro e o estudante, que se opõem entre si e, claro, o marido, como na tríade charuto (de Rudolphe), cigarro (de Leon) e cachimbo (de Charles). O conjunto dessas diferenciações dentro do texto elabora o sentido.

- Enfim, entre as performances semióticas do corpus de interpretação, seja ele constituído preferencialmente de textos, de imagens ou de qualquer outra performance, estabelece-se um terceiro regime que poderia ser chamado "significância", ou melhor ainda, significatividade: ele surge do contraste das formas (e fundos) semióticas de uma performance com outras, dentro do corpus exigido.

Nestes três regimes da significação, do sentido e da significatividade, a interpretação, seja percepção ou descrição, consiste em três operações convergentes: estimativa de semelhanças; discriminação de contrastes até o ponto de oposição; os dois últimos regimes acrescentam a isto a avaliação das transformações internas ou externas à performance considerada.

Devido à recção do global sobre o local, o significado é governado pelo sentido, que, por sua vez, é encontrado sob a recção da significatividade: assim o significado da palavra depende do texto no qual ela é encontrada; e este texto tira seu sentido do corpus ao qual pertence (corpus de elaboração e/ou corpus de leitura) e se estende potencialmente ao conjunto da cultura.

A enformação do signo e a composição do texto tornam possível definir seu teor, definido como um emparelhamento específico entre conteúdo e expressão. Além de seu teor, 
um objeto cultural é definido por seu escopo, resultante da dualidade entre o ponto de vista e a garantia que preside a sua gênese e a sua interpretação. ${ }^{29}$

O projeto diz respeito principalmente ao escopo, à composição do teor: mas os dois estão relacionados. Portanto, o projeto de leitura compreende duas fases não separadas. Por um lado, a fase descritiva nos permite identificar tendências, muitas vezes detectáveis pelos métodos frequencistas da linguística de corpus; por outro lado, nos permite detectar enigmas locais, suscetíveis às inferências bayesianas, e localizáveis por certos testes, como o da distribuição normal reduzida. A fase hermenêutica consistirá em esclarecer a relação problemática entre as tendências gerais e os enigmas locais, segundo a hipótese sempre conjectural de uma síntese "subjetiva", de um Kunstwollen, de um projeto que governaria o estilo específico da obra.

Além dos exemplos que demos, os exemplos literários e mais geralmente artísticos testemunham princípios semióticos que gozam de grande generalidade. Por exemplo, considerar as raízes triliterais das línguas semitas como sementes estruturais das classes de lexemas é amplamente explorado em textos literários e religiosos (por exemplo, o nome Golgotha manifesta a raiz $\mathrm{g} / \mathrm{g}$, que torna possível evocar um crânio, o de Adão, que a iconografia mostra ao pé da cruz, redimido pelo sangue de Cristo). Mas isto também pode ser verdade para a elaboração da terminologia científica.

Em suma, uma vez despojadas de certas exaltações, as múltiplas teorias sobre a origem poética da linguagem (como em Giambattista Vico) ou sobre a poesia como estado fundamental da linguagem (como em Benedetto Croce), poderiam encontrar nas próprias propriedades da semiose, como detectadas e exploradas pelas artes da linguagem, uma explicação, senão uma legitimação: assim, as isofonias e as isotopias resultam de um princípio perceptivo básico: a lei da boa continuação.

\section{Da magia semiótica à ameaça do mito}

Devemos, entretanto, "deixar a iniciativa para as palavras"? Por mais de um século, as experiências de associacionistas, realizadas em escala maciça em pares de palavras, confirmaram as ativações semânticas e expressivas que induziram as relações entre as palavras-fonte e as palavras-alvo. Em um nível mais alto de complexidade, aplicadas recursivamente, as leis da boa continuação, estendidas de forma a forma, transformam-se em leis "mágicas", aquelas que Frazer, inspirado, como Tylor, pelo associacionismo de Hume, denominou como as leis da imitação e a lei do contágio. Ambas foram criticadas e ampliadas por Marcel Mauss em seu Esquisse d'une théorie générale de la magie (Esboço de uma Teoria Geral da Magia), retomadas e transpostas por Malinowski e por Evans-Pritchard, e enfim por Lévi-Strauss, que chega mesmo a relacioná-las à dualidade jakobsoniana entre 
metáfora e metonímia. Estas leis são ambas análogas: uma parte de uma forma engendra ou uma parte da mesma forma (lei de contágio) ou uma parte homóloga de outra forma (lei de imitação ou de simpatia). Elas tecem passo a passo uma rede de correspondências que pode organizar todo o universo semiótico (ver Yocaris (2018), sobre Contemplações). Disso resulta um efeito de profundidade que desenvolvem as teorias místicas da linguagem, de Philo de Alexandria a Walter Benjamin: ela falaria de si mesmo, dizendo as verdades obscuras escondidas em suas raízes. ${ }^{30}$

Espontâneos e incoercíveis, presumivelmente por ativação, os processos de associação por proximidades semânticas ou fonéticas são explorados pela psicanálise nas associações "livres" e se manifestam nos "delírios", especialmente verbais e gráficos, que repetem recursivamente formas impregnadas que se tornaram obsessivas: os "defensores do preciosismo linguístico" e os trabalhos gráficos de certos psicopatas testemunham isso.

Quando ultrapassa um certo limite de associações, uma forma se torna fascinante e assume a autoridade de um "símbolo" no sentido romântico, um ícone que transcende seus contextos. Na ordem mágica, ela perturba e transcende as localizações espaçotemporais. Formas ubíquas que, por seus parentescos, parecem agir à distância, umas das outras, suscitam uma assombração: aqui reconhecemos o espaço do mito, que, embora tenha perdido o esplendor da Fábula, ainda está bem vivo nos discursos populistas inspirados por teologias políticas obsessivas.

Como os Leitmotivs wagnerianos, Moeller van der Brück uma vez teorizou as imagens orientadoras, o Leitbilder. Nunca negadas, mas ainda mais evocativas, não têm nada em comum com os refrões; são aparições, simbolizam forças em presença contra um fundo inquieto, que tem apenas uma função de espera: as palavras rodeiam a figura diretora, como a multidão o Führer, o único ponto fixo, no célebre movimento de câmera de Leni Riefenstahl. A combinação hipnótica cria um bloqueio por confinamento, em um mundo onde tudo remete às mesmas figuras assombrosas, que escondem uma cena não dita, um épico [?] iniciático de aniquilação que não pode e não deve ser figurado.

\section{A semiose como descoberta e criação}

Ampliadas pouco a pouco, as leis de imitação e contágio dão origem a um "efeito de mundo". Os elos que elas tecem constituem uma totalidade mágica e/ou religiosa cujos nós mais conectados são deuses ou espíritos atuantes. Às vezes, centrado ou dominante, o autor estabelece um universo totalizante e toma a atração de Deus ou do demiurgo no universo conectado de sua obra. O acaso, "derrotado palavra por palavra", como diz Mallarmé, cede assim lugar à necessidade da Obra ou de seu substituto contemporâneo, a Escrita. 
Por outro lado, as práticas que favorecem a inibição através da distância crítica, do humor com o uso de formas fixas, permitem controlar a semiose e sua extensão à composição textual, através das reformulações, das rasuras, das normas de gênero e das exigências aleatórias da prática corrente. Nos rascunhos de Flaubert que estudamos, depois de um delírio de associações desde o primeiro ao oitavo, ao nono, $80 \%$ da massa verbal se vê riscada, até um magro resultado no décimo quarto e último rascunho.

De modo mais geral, são os fenômenos de individuação que constituem o signo em seu teor (conteúdo e expressão, ou mais geralmente valore phore), sob a recção de seu escopo, definido ao mesmo tempo pelo ponto de vista enunciativo (que introduz uma distância crítica) e pela garantia (geralmente social) que supõe um mínimo de conformidade com as normas de inteligibilidade e convenção. ${ }^{31}$

Felizmente, mesmo que os signos sejam individuados por ativações semânticas e fonéticas permitidas por germes estruturais, os desvios mistificadores não têm nada de fatal. A literatura sabe como virá-las contra si mesmas. A ciência pode eliminá-las: por exemplo, quando as palavras estrela e barril nomeiam estruturas matemáticas, todas as conotações são excluídas. No nível textual, a luta contra o mito continua, por exemplo, para evitar que a história adventícia se transforme em uma narrativa romanesca. Em todo lugar, no reino das ideias, as ideologias ameaçam, e todo o programa da desconstrução terá sido precisamente o de deslegitimar as ciências (daí os ataques de Derrida contra Saussure) a fim de remistificar o pensamento em favor de várias narrativas identitárias e de teologias políticas.

\section{REFERENCIAS}

Beaudouin, Valérie. 2002. Rythme et mètre du vers classique. Corneille et Racine. Paris: Champion

Benveniste, Émile. 1964. Lettres de Ferdinand de Saussure à Antoine Meillet. Cahiers Ferdinand de Saussure 21. $93-130$.

Cadiot, Pierre \& Visetti, Yves-Marie. 2001. Pour une théorie des formes sémantiques. Paris: PUF.

Cassirer, Ernst. 1938. Le concept de groupe et la théorie de la perception. Journal de psychologie normale et pathologique 35. 368-414.

Cassirer, Ernst. 1972a. La philosophie des formes symboliques. Paris: Minuit. tome 1.

Cassirer, Ernst. 1972b. Débat sur le kantisme et la philosophie (Davos, mars 1929). Paris: Beauchesne. 48-49. (Nachgelassene Manuskripte und Texte (ECN) vol. 17. Hambourg, Meiner, 2014: 108-119).

31 Poder-se-ia encontrar aqui a dualidade entre dopamina, ligada ao comportamento exploratório hedônico, e serotonina participando de sua inibição; ou, em termos mais convencionais, entre coração e razão. 
Cassirer, Ernst. 1991. L'objet de la science de la culture. In Logique des sciences de la culture. Paris: Éditions du Cerf.

Cassirer, Ernst. 2008. Nachgelassene Manuskripte und Texte, vol. 8. Hamburg: Meiner.

Guiraud, Pierre. 1967. Les structures étymologiques du lexique français. Paris: Larousse.

Kurts-Woeste, Lia. 2020. "Enjeux d'une sémiotique non logocentrée: prospections à partir de la musique et de la notion de "significativité". In Astrid Guillaume et Lia Kurts- Woeste (éds.), Faire sens, faire science. ParisLondres: ISTE.

Mallarmé, Stéphane. 1998. CEuvres complètes, I. Paris: Gallimard.

Naville, Adrien. 1901. Nouvelle classilcation des sciences. Étude philosophique. Paris: Alcan.

Nicolaï, Robert. (no prelo). Parcours sémiotiques, ou les mots des hommes. Une anthropologie langagière.

Piotrowski, David. 2017. Morphogenesis of the Sign. New York: Springer.

Poe, Edgar. [1864] 1982. La genèse d'un poème. Poèmes suivis de La genèse d'un poème, 159-177. Paris: Gallimard.

Rastier, François. 1987. Sémantique interprétative. Paris: PUF.

Rastier, François. 1989. Sens et textualité. Paris: Hachette (rééd. Limoges, Lambert-Lucas, 2016).

Rastier, François. 1991. Sémantique et recherches cognitives. Paris: PUF.

Rastier, François. 2006. Formes sémantiques et textualité. Langages 163. 99-114.

Rastier, François. 2007. Passages. Corpus 6. 125-152.

Rastier, François. 2011. La mesure et le grain. Sémantique de corpus. Paris: Champion.

Rastier, François. 2016. Créer: Image, Langage, Virtuel. Paris-Madrid: Casimiro.

Rastier, François. 2018a. Unités et formes textuelles. Semiotica 223.13-23.

Rastier, François. 2018b. Faire sens. De la cognition à la culture. Paris: Classiques Garnier.

Rastier, François. 2018c. Mondes à l'envers - De Chamfort à Samuel Beckett. Paris: Classiques Garnier.

Saussure, Ferdinand de. 2013. Anagrammes homériques, Pierre-Yves Testenoire (éd.). Limoges: LambertLucas, 390.

Scheier, Claus-Artur. 1993. Die Sprache spricht. Heideggers Tautologien. Zeitschrift für philosophische Forschung, Bd. 47(1). 60-74.

Sedaghat, Amir. 2015. Le sou!sme de Roumi reçu et perçu dans les mondes anglophone et francophone: étude des traductions anglaises et françaises. Paris: Université Sorbonne Paris Cité.

Testenoire, Pierre-Yves. 2013. Ferdinand de Saussure à la recherche des anagrammes. Limoges: LambertLucas.

Testenoire, Pierre-Yves (no prelo). Saussure/Mallarmé. autopsie d'un couplage.

Thom, René. 1980. Modèles mathématiques de la morphogenèse. Paris: Christian Bourgois.

Valéry, Paul. 1957. OEuvres, I. Paris: Gallimard.

Yocaris, llias. 2018. "Pyramide du temple, voûte du sépulcre " : le fonctionnement holistique de l'écriture dans Les Contemplations. Texto! Textes et cultures XXIII(4) (en ligne). 